\title{
Titte: \\ ATTACK OPTIMIZATION FOR UNEQUAL MODERATE FORCES
}

Author(s):

Gregory H. Canavan, DDP

Submitted to:

For discussions outside the Laboratory

Date: June 1997

\section{Los Alamos}

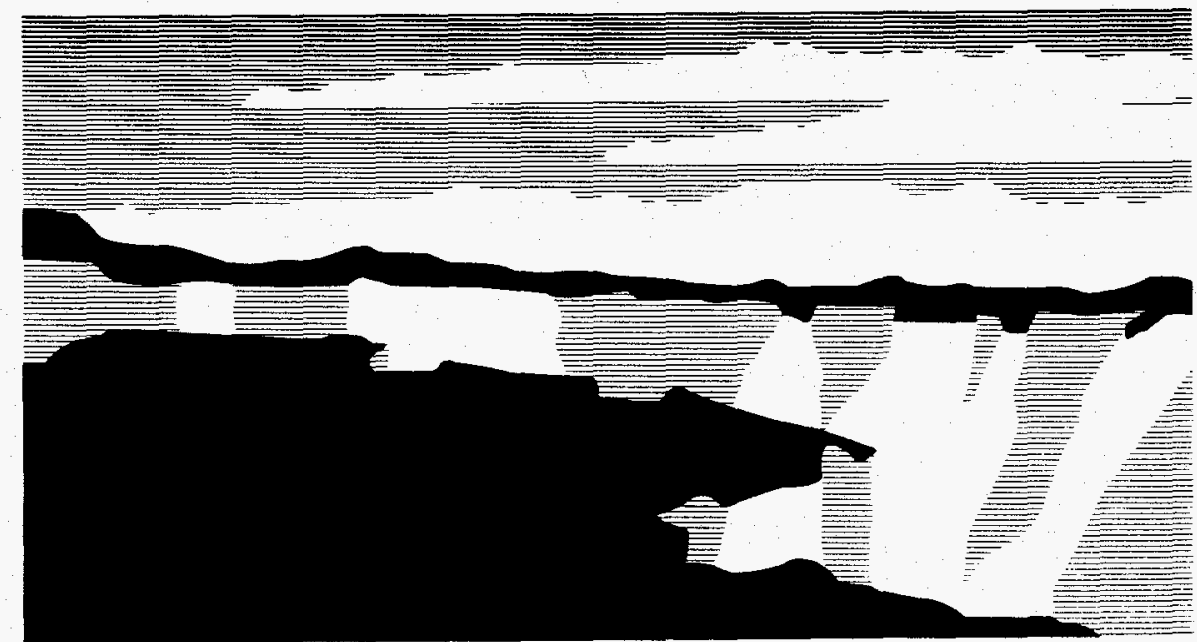

Los Alamos National Laboratory, an affirmative action/equal opportunity employer, is operated by the University of California for the U.S. Department of Energy under contract W-7405-ENG-36. By acceptance of this article, the publisher recognizes that the U.S. Government retains a nonexclusive, royalty-free license to publish or reproduce the published form of this contribution, or to allow others to do so, for U.S. Government purposes. The Los Alamos National Laboratory requests that the publisher identify this article as work performed under the auspices of the U.S. Department of Energy. 


\section{DISCLAIMIER}

Portions of this document may be illegible in electronic image products. Images are produced from the best available original document. 


\title{
ATTACK OPTIMIZATION FOR UNEQUAL MODERATE FORCES
}

\author{
Gregory H. Canavan
}

\begin{abstract}
Attack allocation optimizations produce stability indices for unsymmetrical forces that indicate significant regions of both stability and instability and that have their minimum values roughly when the two sides have equal forces.
\end{abstract}

This note derives combined stability indices for unsymmetrical offensive force configurations. The indices are based on optimal allocations of offensive missiles between vulnerable missiles and value based on the minimization of first strike cost, which is done analytically. Exchanges are modeled probabalistically and their results are converted into first and second strike costs through approximations to the damage to the value target sets held at risk. The stability index is the product of the ratio of first to second strike costs seen by the two sides.

Optimal allocations scale directly on the opponent's vulnerable missiles, inversely on one's own total weapons, and only logarithmically on the attacker's damage preference, kill probability, and relative target set. The defender's allocation scales in a similar manner on the attacker's parameters. First and second strike magnitudes increase roughly linearly for the side with greater forces and decrease linearly for the side with fewer. Conversely, the first and second strike magnitudes decrease for the side with greater forces and increase for the side with fewer. These trends are derived and discussed analytically.

The resulting stability indices exhibit a minimum where the two sides have roughly equal forces. If one side has much larger forces than the other, his costs drop to levels low enough that he is relatively insensitive to whether he strikes first or second. These calculations are performed with the analytic attack allocation appropriate for moderate forces, so some differences could be expected for the largest of the forces considered.

Model. Earlier notes have shown that it is possible to model exchanges between equal missile missiles forces in terms of the first, F, and second, S, strikes one side could deliver. That analysis can be extended to unequal forces by treating the strikes $F$ ' and $S^{\prime}$ that the second side (denoted by primes for simplicity) could deliver. Unprime has $\mathbf{M}$ vulnerable missiles with $\mathrm{m}$ weapons each and $\mathrm{N}$ survivable missiles with $\mathrm{n}$ weapons each, and prime has $\mathrm{M}^{\prime}$ vulnerable missiles with m' weapons each and N' survivable missiles with n' weapons each. If unprime is the first striker and a fraction $\mathrm{f}$ of his weapons is directed at prime's vulnerable missiles, unprime's first strike on value targets is

$$
F=(1-f)(m M+n N) \text {. }
$$

The average number of weapons delivered on each of prime's vulnerable missile is 


$$
r=f(m M+n N) / M^{\prime} .
$$

For $r$ large, their average probability of survival is approximately 1

$$
\mathrm{Q} \approx \mathrm{q}^{\mathrm{r}} \approx \mathrm{e}^{\mathrm{fW} \ln q / \mathrm{M}^{\prime}}
$$

where $q=1-p$, and $p$ is the attacking missile's single shot probability of kill, which is taken to be the same for all missiles. Prime's second strike is

$$
S^{\prime}=m^{\prime} M^{\prime} Q+n^{\prime} N^{\prime} \approx m^{\prime} M^{\prime} q^{r}+n^{\prime} N^{\prime} \text {, }
$$

which is delivered on value, as missiles remaining at the end of the exchange are taken to have no value in this two strike engagement. The corresponding equations for prime's strike can be derived either by repeating the logic from his perspective or simply by conjugating the equations above, i.e., interchanging primed and unprimed symbols in Eqs. (1) - (4).

Costs and stability index. These first and second strike magnitudes can be converted into the costs of striking first and second through exponential approximations to the fractions of value targets destroyed. Damage to self and incomplete damage to the other are incommensurate, but a conventional approximation is their weighted sum ${ }^{2}$

$$
C_{1}=\left(1-e^{-k S^{\prime}}+L e^{-k} F\right) /(1+L) \text {, }
$$

where $k=k^{\prime} \approx 0.001$ are constants that are roughly equal to the inverse of the size of the military value target sets held at risk by each side 3 and $\mathrm{L}$ is a constant that represents the attacker's relative preference for inflicting damage on the other and preventing damage to self. $\mathrm{L}$ small means the first striker is primarily concerned about denying damage; $L$ large means he is more concerned about inflicting damage on the other. The assumption that $\mathrm{L} \leq 1$ and construction of $C_{1}$ as a weighted average is plausible but not unique. ${ }^{4}$ The normalized second strike costs cost to the second striker is

$$
\mathrm{C}_{2}{ }^{\prime}=\left(1-\mathrm{e}^{-\mathrm{k}^{\prime} \mathrm{F}}+\mathrm{L}^{\prime} \mathrm{e}^{-\mathrm{k} S^{\prime}}\right) /\left(1+\mathrm{L}^{\prime}\right),
$$

which uses a different constant $L$ ' reflecting prime's attack preference ${ }^{5}$ There is some arbitrariness in converting $C_{1}$ and $C_{2}$ into stability indices. 6 The ratio of costs, $C_{1} / C_{2}$, is used for equal forces, so for unequal forces the calculations below extend that index to

$$
\text { Index }=\mathrm{I} \times \mathrm{I}^{\prime}=\left(\mathrm{C}_{1} / \mathrm{C}_{2}\right)\left(\mathrm{C}_{1}{ }^{\prime} / \mathrm{C}_{2}{ }^{\prime}\right) \text {, }
$$

where $C_{2}$ and $C_{1}$ ' are the conjugates of Eqs. (6) and (5), respectively.

Optimal attack allocation for unprime amounts to choosing $f$ that minimizes the first strike cost $\mathrm{C}_{1}$, which is accomplished by differentiating Eq. (5) with respect to $\mathrm{f}$, setting the result to zero, and solving for $\mathrm{f}$. For large forces the resulting equation is transcendental, but the moderate force $(\mathrm{F}, \mathrm{S}<1 / \mathrm{k})$ optima holds sufficiently accurately for moderate forces, so that

$$
(1+L) C_{1} \approx k\left(m^{\prime} M^{\prime} e^{f W l n q} / M^{\prime}+n^{\prime} N^{\prime}\right)+L\left[1-k^{\prime}(1-f) W\right],
$$

whose derivative with respect to $\mathrm{f}$ has a minimum at

$$
f_{\text {opt }}=\left(M^{\prime} / W \operatorname{lnq}\right) \ln \left(-\mathrm{Lk}^{\prime} / \mathrm{km} \operatorname{lnq}\right) \text {. }
$$


Several important scalings follow from the form of $\mathrm{f}_{\text {opt }}$. It scales directly on the opponent's vulnerable missiles $M^{\prime}$ and inversely on one's own total weapons $\mathrm{W}=\mathrm{mM}+\mathrm{nN}$. These principal scalings should be obvious. In a first strike, the distinction between vulnerable and survivable missiles is not significant and the degree of fractionation of each is unimportant as well, so that only $\mathrm{W}$ should matter. And it is plausible that the number of weapons allocated to missiles should be proportional to the number of missiles, $\mathrm{Wf}_{\mathrm{opt}} \sim \mathrm{M}^{\prime}$, as shown. If in addition, the number of vulnerable weapons $\mathrm{mM}$ is proportional to the number of survivable weapons $\mathrm{mM}$ $\sim \mathrm{nN}$, then $\mathrm{f}_{\text {opt }} \alpha \mathrm{M}^{\prime} / \mathrm{mM}$., i.e., it scales in proportion to the relative number of the opponent's vulnerable missiles. If the number of vulnerable missiles on each sides change proportionally, $f_{\text {opt }} \alpha 1 / \mathrm{m}$. If the weapons per missile does not change, $f_{\text {opt }}$ is constant. For $m=n$, i.e., equal fractionation of vulnerable and survivable weapons, $W=m(M+N)$, so that the allocation only depends on the total number of missiles, not on whether they are vulnerable or survivable. Note that to first order it is unprime's weapons per missile that determines his allocation; prime's weapons per missile enters only logarithmically, as do $\mathrm{L}, \mathrm{k}$, and $\mathrm{k}$ '. The allocation decreases with $\mathrm{L}$ as before. It is insensitive to prime's $\mathrm{L}^{\prime}$, as that does not enter $\mathrm{C}_{1}$.

Figure 1 shows unprime's allocation of his $M=N=200$ triple warhead missiles primes vulnerable missiles as a function of the number of prime's $M^{\prime}=N^{\prime}$ triple warhead missiles. For $M^{\prime}=N^{\prime}=50, f_{\text {opt }} \approx 0.1$. It grows linearly with $M^{\prime}$ to about 0.9 at $M^{\prime}=450$ for $L=0.3$. For $L=1$ it increases linearly from $\approx 0.5$ to 0.4 . In either case the number of weapons delivered on vulnerable missiles is roughly adequate to suppress them significantly, i.e., $\mathrm{f}_{\mathrm{opt}} \mathrm{W} \sim \mathrm{M}^{\prime}$, e.g. 0.2 $\times 3 \times(200+200) \sim 240$, which is adequate to suppress prime's 100 vulnerable missiles for that exchange.

The variation of allocation with forces is simpler to display for the unsymmetric forces $m$ $=n, M=N, m^{\prime}=n^{\prime}$, and $M^{\prime}=N^{\prime}$ but $M \neq M^{\prime}$, which is shown in Fig. 2. The allocation for unprime is the same as the $\mathrm{L}=0.3$ curve of Fig. 1 . The other curve is for $L^{\prime}=0.5$. The prime allocation $\mathrm{f}^{\prime}$ can be obtained from Eq. (9) by conjugation and is

$$
f_{\text {opt }}=\left(M / W^{\prime} l n q '\right) \ln \left(-L^{\prime} k / k^{\prime} m l n q '\right) \text {, }
$$

which varies primarily as $f_{o p t} \sim\left(M / W^{\prime}\right) \ln \left(-L^{\prime}\right)$, i.e., for fixed $M, f_{\text {opt }}$ falls as $\sim 1 / W^{\prime}$, as shown.

First and second attacks. The first and second strikes that either side could mount with these unsymmetric forces are shown in Fig. 3. Unprime's first strike falls with $M$ ', reflecting the linear increase of $f$ with $M^{\prime}$ in Fig. 1. Unprime's second strike is roughly constant because prime's optimal allocation $\mathrm{f}_{\text {opt }} \sim 1 / \mathrm{W}^{\prime}$ retains a roughly constant number of weapons on prime's vulnerable missiles as $W^{\prime}$ increases, and hence a roughly constant contribution from them to the second strike. Prime's first strike grows roughly linearly because of the growth of W'. His second strike grows roughly linearly because prime's optimal allocation $f_{\text {opt }} \sim M^{\prime}$ again retains a roughly 
constant number of weapons per unprime vulnerable as $W^{\prime}$ increases, which produces a roughly constant second strike.

First and second strike costs. Figure 4 shows the first and second strike costs for each side for these unsymmetric forces. Unprime's first and second strike costs increase with $\mathbf{M}^{\prime}$, reflecting the scaling $\mathrm{f}_{\mathrm{opt}} \sim \mathrm{M}^{\prime} / \mathrm{W}$, and

$$
(1+L) C_{1} \approx k m^{\prime} M^{\prime}\left(e^{f W} \ln q / M^{\prime}+1\right)+L\left[1-k^{\prime}(1-f) W\right],
$$

so that

$$
\Delta C_{1} / \mathrm{k} \sim \mathrm{m}^{\prime} \Delta \mathrm{M}^{\prime}+\mathrm{L} \Delta \mathrm{M}^{\prime},
$$

in which both the first term for the second strike costs and the second for the cost of the unachieved first strike damage increase linearly with $\Delta M^{\prime}$ until they saturate for $M^{\prime} \gg M^{\prime}$. Unprime's second strike cost increase because his second strike does not increase while prime's first strike increases with $\mathbf{M}^{\prime}$.

Prime's costs decrease with $M^{\prime}$. His first strike allocation decreases as $f_{o p t} \sim M / W^{\prime}$, which produces

$$
\begin{aligned}
& \mathrm{C}_{1^{\prime}} \sim \mathrm{k}^{\prime} \mathrm{mM}\left(\mathrm{e}^{\mathrm{f}^{\prime} \mathrm{W}^{\prime} \ln q / M}+1\right)+\mathrm{L}^{\prime}\left[1-\mathrm{k}\left(1-\mathrm{f}^{\prime}\right) \mathrm{W}^{\prime}\right] \\
& \text { - constant + L'[1 - k(1 - M/W') } \left.\mathrm{W}^{\prime}\right] \text {, }
\end{aligned}
$$

so that

$$
\Delta \mathrm{C}_{1}{ }^{\prime} \sim \text { constant - L' } \mathrm{k}^{\prime} \Delta \mathrm{W}^{\prime},
$$

as seen for $M^{\prime}<<M$. Prime's second strike costs decrease with $M^{\prime}$ because his second strike is increasing rapidly while unprime's first strike is decreasing, as shown on Fig. 3.

Stability indices. These costs are integrated in the stability indices of Eq. (7), which are shown in Fig. 5. The index I for unprime approaches unity at large $\mathrm{M}$ ', falls for intermediate values, and climbs sharply for $M^{\prime}<150$. The reasons can be seen from Fig. 4 in which the first and second strike costs cross at $M^{\prime} \approx 450, C_{2}$ is larger than $C_{1}$ down to $\approx 125$, and $C_{1}>C_{2}$ for smaller $\mathbf{M}^{\prime}$, which indicates strong stability.

The index $I^{\prime}$ for prime is large at large $M^{\prime}$, falls below unity at $M^{\prime} \approx 350$, and approaches an asymptote of about 0.8 for smaller values. Figure 4 shows that this results from the linear decrease of $C_{2}{ }^{\prime}$, which falls below $C_{1}{ }^{\prime}$, at $M^{\prime} \approx 300$, and the fact that $C_{1}{ }^{\prime}$ and $C_{2}{ }^{\prime}$ are parallel at small $\mathrm{M}^{\prime}$, where both are very large.

The overall index I $x I^{\prime}$ has a minimum at about $M^{\prime}=M=200$, where it has a value of about 0.75 . For larger values of $M^{\prime}$ the index is large because of the large value of $I^{\prime}$, which results from the dominant position of prime there. Because of the saturation of $\mathrm{C}_{1}{ }^{\prime}$ discussed above, $\mathrm{C}_{2}$ ' falls well below $\mathrm{C}_{1}$ ', which produces strong stability. At small values of $\mathrm{M}^{\prime}$ the index is large because of the large value of $\mathrm{I}$, which results from the dominant position of unprime. Because $\mathrm{C}_{2}$ falls more rapidly than $\mathrm{C}_{1}{ }^{\prime}$, that produces strong stability there as well. It is at 
intermediate values where the two sides have comparable values that the combined index takes its minimum value.

Summary and conclusions. This note derives combined stability indices for unsymmetrical offensive force configurations. They are based on optimal offensive missile allocations between missiles and value based on the minimization of the first strike costs, which is done analytically. Exchanges are modeled probabalistically, and their results are converted into first and second strike costs through approximations to the damage to the value target sets held at risk. The stability index is taken to be the product of the ratio of first to second strike costs seen by the two sides.

Several important scalings follow from the form of the optimal allocation, which scales directly on the opponent's vulnerable missiles, inversely on one's own total weapons, and only logarithmically on the attacker's damage preference, kill probability, and relative target set. The defender's allocation scales in a similar manner on the attacker's parameters. This model leads to first and second strike magnitudes that increase roughly linearly for the side with greater forces and decrease linearly for the side with fewer. Conversely, the first and second strike magnitudes decrease for the side with greater forces and increase for the side with fewer. These trends can be isolated and discussed analytically.

The resulting stability indices exhibit a minimum about where the two sides have roughly equal forces. If one side has much larger forces than the other, his costs drop to levels low enough that he is relatively insensitive to whether he strikes first or second. It should be noted that these calculations are all performed with the analytic attack allocation appropriate for moderate forces, so some differences could be expected for the largest of the forces considered.

\section{DISCLAIMER}

This report was prepared as an account of work sponsored by an agency of the United States Government. Neither the United States Government nor any agency thereof, nor any of their employees, makes any warranty, express or implied, or assumes any legal liability or responsibility for the accuracy, completeness, or usefulness of any information, apparatus, product, or process disclosed, or represents that its use would not infringe privately owned rights. Reference herein to any specific commercial product, process, or service by trade name, trademark, manufacturer, or otherwise does not necessarily constitute or imply its endorsement, recommendation, or favoring by the United States Government or any agency thereof. The views and opinions of authors expressed herein do not necessarily state or reflect those of the United States Government or any agency thereof. 


\section{References}

1. G. Canavan, "Probability of Survival from Multiple Weapon Attacks," Los Alamos report LAUR-97-, February 1997.

2. G. Kent and R. DeValk, "Strategic Defenses and the Transition to Assured Survival," RAND Report R-3369-AF, October, 1986.

3. G. Canavan, "Costs of Strikes Between Vulnerable Missile Forces," Los Alamos report LAUR-97-, February 1997.

4. G. Canavan, "Stability at Symmetric Low Force Levels," op. cit.

5. G. Canavan, "Destabilizing Effects of Perceptions," Los Alamos LA-UR-96-1742, May 1996

6. G. Canavan, "Impact of Differing Metrics on Crisis Stability Analyses," A. Zichichi ed., International Seminar on Nuclear War and Planetary Emergencies, 18th Session: Global Stability Through Disarmament (London, World Scientific, 1993). 


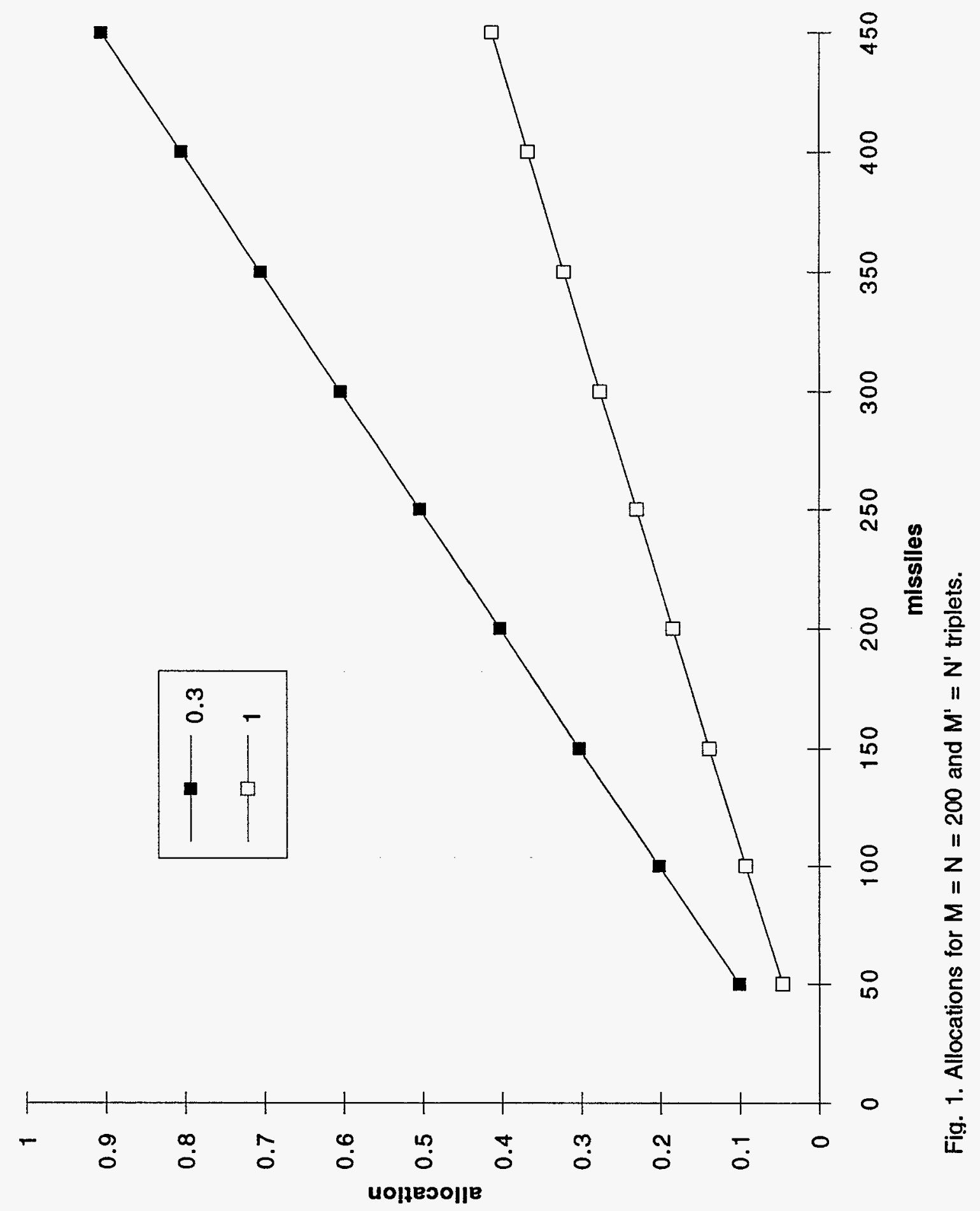




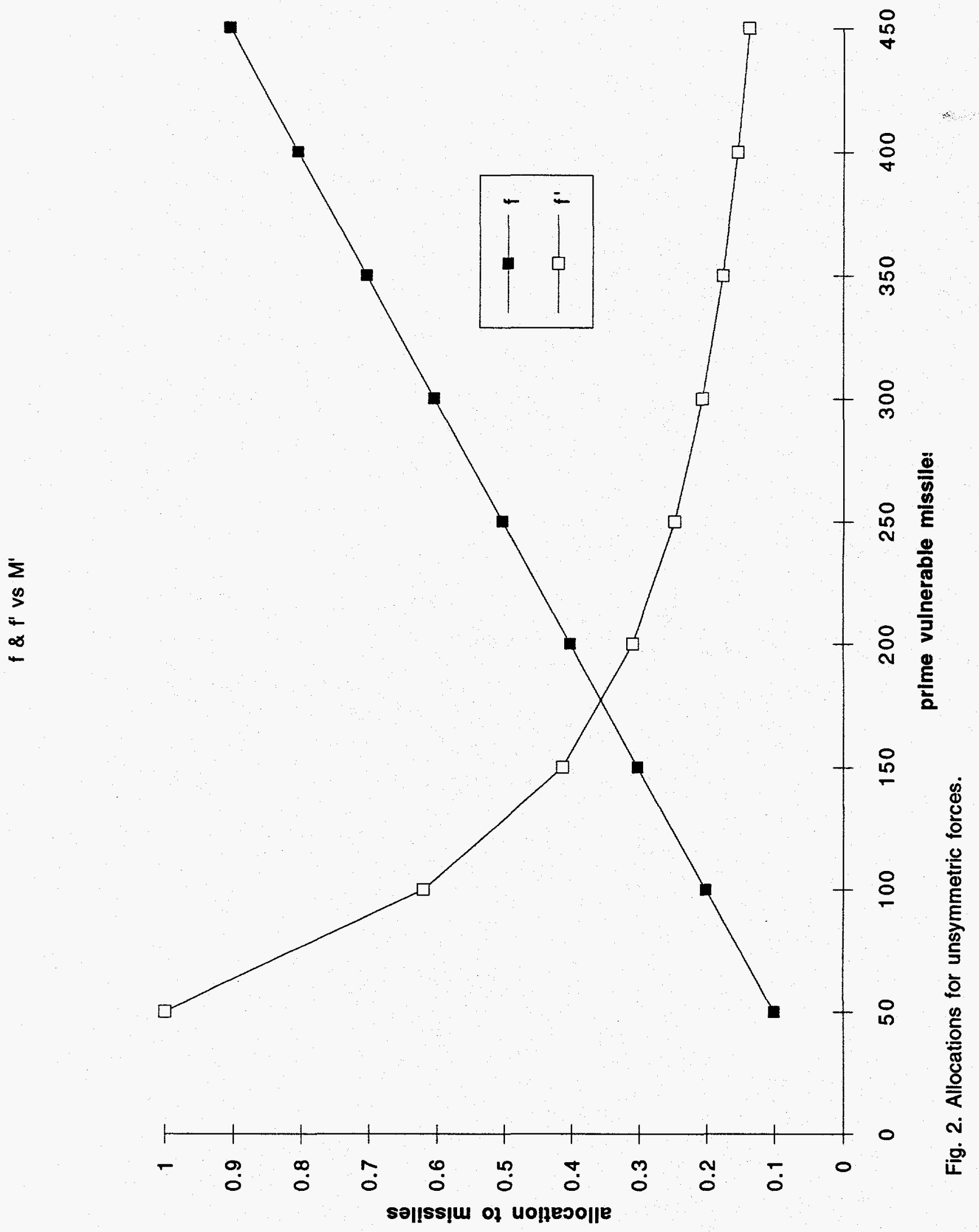


$1 \&$ 2nd strikes vs $M^{\prime}$

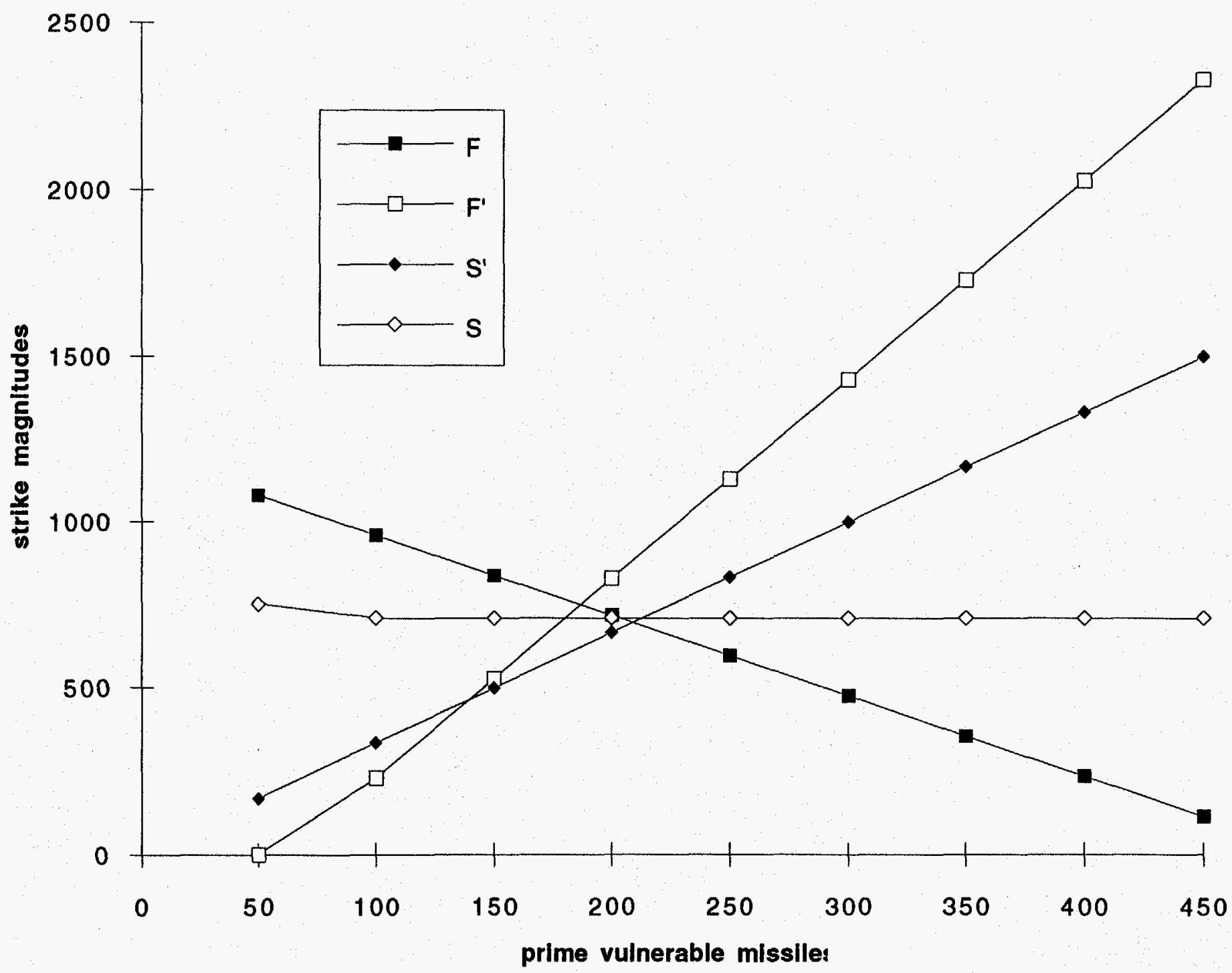

Fig. 3. First and second strikes for unsymmetric forces. 


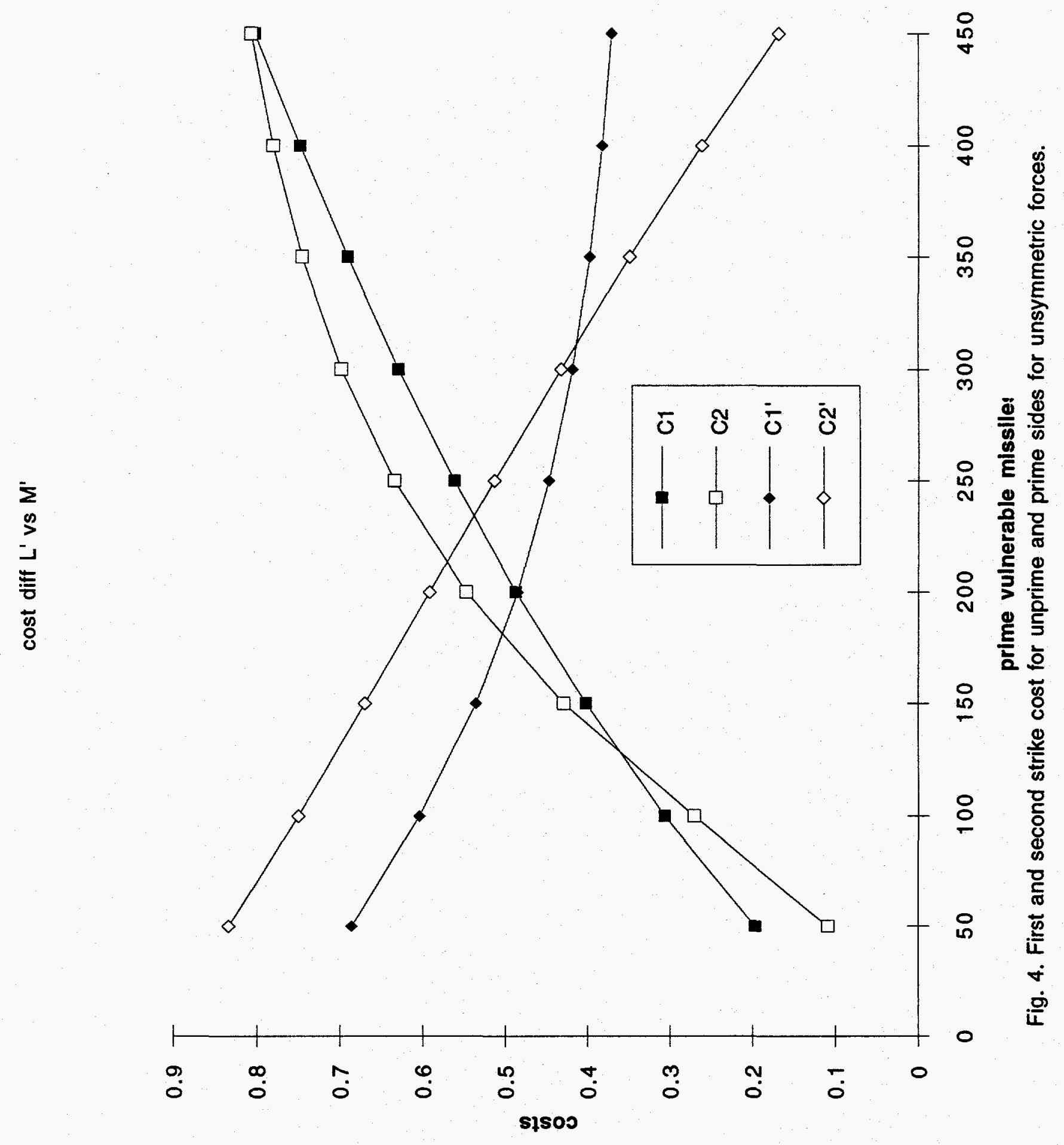




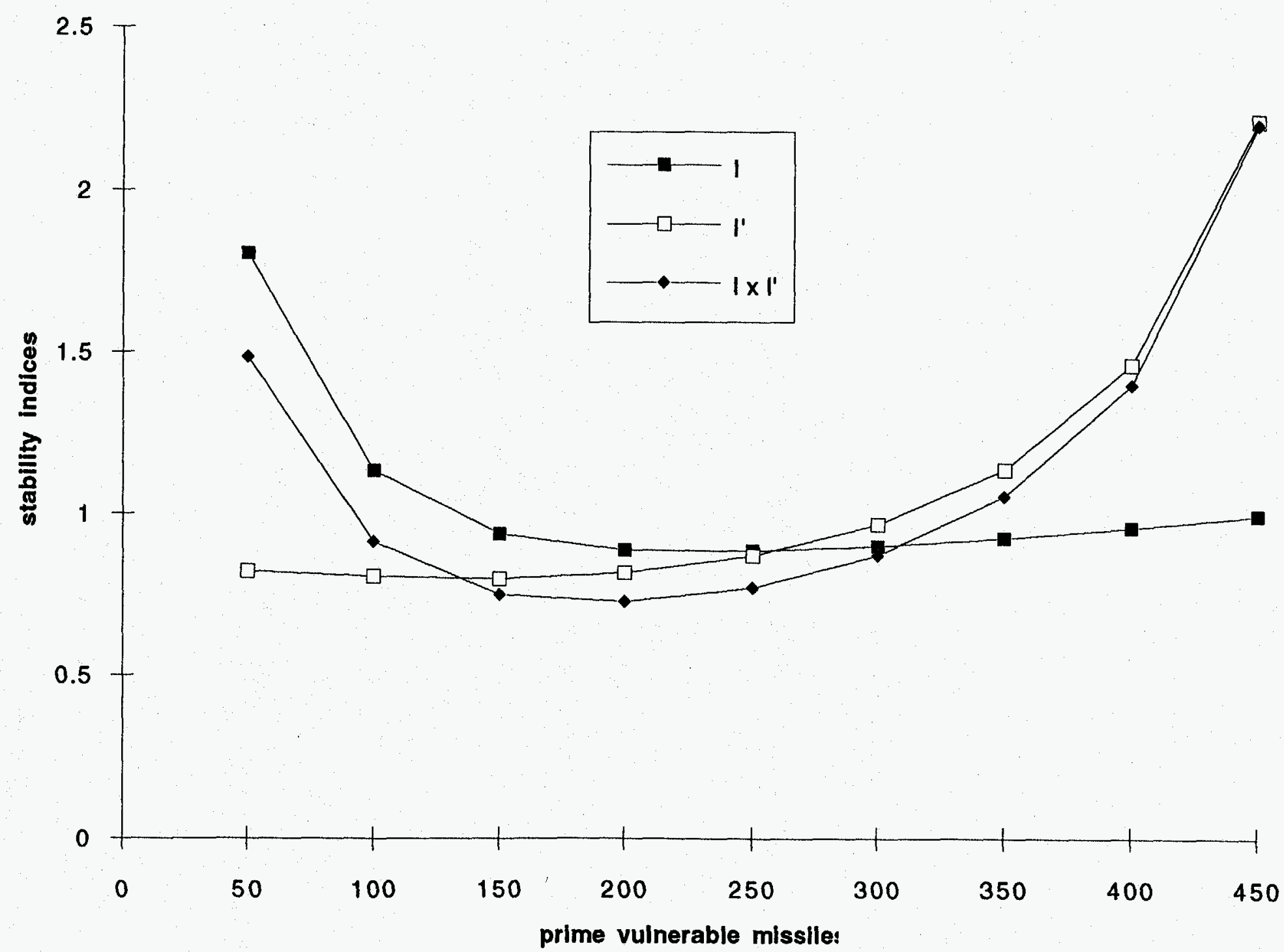

Fig. 5. Stability indices for unsymmetric forces. 